\title{
Biologia reprodutiva e ausência de frutificação de Aloe saponaria (Aiton) Haw. (Xanthorrhoeaceae) fora do local de origem
}

CORREDOR-PRADO, J.P.'; DE CONTI, D.1; SEZERINO, A.1; GUERRA, M.P.1; ORTH, A.I.*1 1Universidade Federal de Santa Catarina, Departamento de Fitotecnia, Centro de Ciências Agrárias, Programa de Pós-Graduação em Recursos Genéticos Vegetais, Rodovia Admar Gonzaga, 1346, CEP 88034-001, Florianópolis, SC, Brasil. *Autor para correspondência: afonso.orth@ufsc.br

RESUMO: O gênero Aloe, originário principalmente da África, tem atualmente uma ampla distribuição no mundo. No entanto, são poucas as regiões que têm realizado estudos quanto ao sistema reprodutivo. $O$ objetivo do presente trabalho foi analisar as características e o comportamento reprodutivo de Aloe saponaria em Florianópolis, Santa Catarina. Foram conduzidos estudos sobre sua morfologia e biologia floral, visitantes florais e sistema reprodutivo. Esta espécie apresentou uma inflorescência por planta, com um comprimento de $105 \pm 0,1$ cm e $267 \pm 92,7$ flores. A razão pólen/óvulo sugere que a espécie é xenogâmica. O volume e concentração de sólidos solúveis totais do néctar potencial foi 16,6 \pm 6,3 $\mu \mathrm{L}$ e $22 \pm 2,4{ }^{\circ}$ Brix respectivamente. O néctar instantâneo não apresentou diferenças significativas nos períodos avaliados (9:00h e 15:00h) e o estigma permaneceu receptivo até o segundo dia após a antese. Foram coletados 110 insetos visitantes florais, dos quais 61,8\% foram indivíduos de Trigona spinipes. Entretanto, nos testes de polinização não foi observada frutificação efetiva, indicando que a propagação vegetativa é o principal tipo de reprodução usado nessa população. Isto pode estar relacionado a um mecanismo de autoincompatibilidade esporofítica, a anormalidades cromossômicas durante a formação do pólen, as condições climáticas, e a escassa variabilidade genética no local de estudo.

Palavras-chave: Aloe, autoincompatibilidade esporofítica, polinização, visitantes florais

\begin{abstract}
Reproductive biology and absence of fruiting of Aloe saponaria (Aiton) Haw. (Xanthorrhoeaceae) outside its place of origin. The Aloe genus, originating mainly from Africa, currently has a wide distribution in the world. However, in few regions studies about the reproductive system have been carried on. The aim e of this study was to analyze the characteristics and reproductive performance of the Aloesaponaria in Florianópolis, Santa Catarina. The morphology, floral biology, flower visitors and the reproductive system were determined. The plants presented an inflorescence per plant, with $105 \pm 0,1 \mathrm{~cm}$ in length and 267 \pm 92.7 flowers. The pollen/ovule ratio suggested that the species is xenogamic. The volume and concentration of total soluble solids in the potential nectar were $16.6 \pm 6.3 \mu \mathrm{L}$ and $22 \pm 2.4^{\circ} \mathrm{Brix}$, respectively. The instant nectar showed no significant differences between the evaluated periods (9:00h and 15:00h) and the stigma remained receptive until the second day the after anthesis. 110 insects were collected, from which $61.8 \%$ were from the Trigona spinipes species. However, in the pollination tests the fruit set was not observation, indicating that vegetative propagation is the main type of reproduction used by this population. This may be related to a mechanism of sporophytic self-incompatibility, to chromosomal abnormalities during the formation of pollen, to weather conditions, and to the low genetic variability at the study site.
\end{abstract}

Keywords: Aloe, pollination, floral visitors, sporophytic self-incompatibility

\section{INTRODUCÃO}

O gênero Aloe compreende cerca de 500 espécies, possuindo uma ampla diversidade que inclui ervas perenes, arbustos e pequenas árvores que em geral se caracterizam por suas folhas grossas e suculentas com margem espinhosa (Smith \& Steyn, 2004; Grace et al., 2010). A maioria das espécies de Aloe ocorre no sudeste do continente Africano, na Península Arábica e nas ilhas do

Recebido para publicação em 16/04/2014 
Oceano Índico (Newton, 2004; Grace et al., 2010). Sendo Sudáfrica com \pm 140 espécies, o país com maior diversidade de Aloe no continente Africano (Klopper et al., 2009). A espécie Aloe vera tem sido comercializada desde o século IV a.C., resultando na sua distribuição ao longo das rotas comerciais desde a Península Arábica para o Mediterrâneo, o subcontinente indiano, as Américas e o Caribe, onde foi naturalizada (Grace, 2011). No entanto, são poucas as espécies do gênero Aloe que se tornaram invasores fora de suas distribuições naturais (Grace, 2011). No Brasil, esse táxon foi introduzido e os representantes são empregados como ornamentais e medicinais (Souza \& Lorenzi, 2008).

Devido à grande diversidade do gênero e às várias formas pelas quais as Aloes são valorizadas no mundo, são necessárias medidas de conservação efetivas e enfoques políticos para essas espécies sejam usadas de forma sustentável (Grace, 2011). Os membros do gênero Aloe têm grande variedade de usos comerciais (Mascola et al., 2004). Sua atração estética, a relativa facilidade de cultivo, e a capacidade de hibridizar, dotaram as plantas desse gênero de uma popularidade significativa na horticultura (Van Wyk \& Smith, 2008). Embora A. vera seja uma espécie muito pesquisada e explorada, existem outras espécies do gênero que podem ter potenciais valores econômicos e medicinais. Por exemplo, Aloe saponaria sinônimo de A. maculata All. (Eggli et al., 2001), é uma boa alternativa da $A$. vera no uso antifúngico para manter a qualidade dos frutos de várias espécies (Zapata et al., 2013). Trabalhos relacionados ao uso farmacológico, mostram que essa espécie pode ser útil para o estudo do dano oxidativo nas células e tecidos (Yoo et al., 2008), para contribuir na inibição da proliferação de células tumorais (Sampedro et al., 2004) e como anti-inflamatório nas lesões térmicas (Silva et al., 2013).

Assim como outros gêneros muito diversos, estudos completos e detalhados da taxonomia e biologia de Aloe são difíceis, e até hoje a pesquisa tem focado em subconjuntos geográficos ou taxonômicos (Grace, 2011). Dessa forma, trabalhos relacionados à biologia reprodutiva, têm sido realizados principalmente na África (Symes \& Nicolson, 2008; Botes et al., 2009; Hargreaves et al., 2010, 2012,), sendo poucos com espécies naturalizadas fora do local de origem (Imery-Buiza \& Cárdenas-Ramírez, 2006; 2008; Velásquez-Arenas \& Imery-Buiza, 2008). Considerando que o sistema reprodutivo das plantas é resultado da interação das suas próprias características reprodutivas com o ambiente (Dafni et al., 2005), são necessárias informações básicas que permitam uma melhor compreensão das formas de dispersão e das causas do sucesso das espécies em ambientes não-nativos. Por exemplo, populações naturais de A. vera na África têm frutificação bem sucedida, ao contrário das populações naturalizadas na Venezuela, que não formam frutos apesar de ocorrer visitas frequentes de numerosos polinizadores (Imery-Buiza \& Cequea-Ruiz, 2008). Da mesma forma, estudos indicam que autopolinizações artificiais sugerem autocompatibilidade na espécie A. saponaria quando está fora do local de origem (Imery-Buiza \& Cequea-Ruiz, 2008). Porém, avaliações realizadas em Sudáfrica, indicam que essa espécie, entre outras Aloe parece ser autoincompatível (Hargreaves et al., 2012).

O conhecimento da biologia floral, e do sistema reprodutivo, são aspectos essenciais para a compreensão da biologia reprodutiva de determinada espécie. Essas informações sugerem como os genes são recombinados e mantidos para a perpetuação da variabilidade genética (Sebbenn et al., 1999), considerando, que nas populações com reprodução assexuada proporciona-se indivíduos genotipicamente idênticos; nas populações autógamas os gametas que se unem provêm da mesma planta, produzindo consequentemente plantas homozigotas; e nas populações alógamas há uma recombinação genética constante, já que os gametas provêm de indivíduos distintos, originando plantas heterozigotas (Bueno et al, 2006). Desta maneira, esse tipo de informações sobre $A$. saponaria, permitiriam aprimorar os cruzamentos em programas de melhoramento genético do gênero Aloe, permitiriam desenvolver programas de conservação e inclusive poderiam oferecer estratégias de cultivo para produção com fins medicinais no Brasil. Neste sentido, e considerando o escasso conhecimento sobre a biologia reprodutiva do gênero Aloe no sul do Brasil, e a sua importância medicinal e agroindustrial, o objetivo deste trabalho foi analisar as características e o comportamento reprodutivo da espécie $A$. saponaria em população ex-situ localizada em Florianópolis (Santa Catarina).

\section{MATERIAL E MÉTODOS Área de Estudo}

Os estudos foram conduzidos no Centro de Treinamento da Empresa de Pesquisa Agropecuária e Extensão Rural de Santa Catarina - Epagri, (área sob influência antrópica) localizado no município de Florianópolis, na Ilha de Santa Catarina (27 $34^{\prime} 49^{\prime \prime}$ S; 48³0'22" O). O clima se enquadra no tipo Cfa na classificação de Köppen (1948), com temperaturas médias anuais de $22^{\circ} \mathrm{C}, 1.600 \mathrm{~mm}$ de precipitação pluviométrica e $82 \%$ de umidade relativa do ar (Cecca, 1997). O material testemunho de A. saponaria (Aiton) Haw. (Xanthorrhoeaceae), está depositado como exsicata no Herbário FLOR/CCB/UFSC no 51448. 


\section{Morfologia e biologia floral}

O comprimento das inflorescências foi medido em 10 indivíduos, desde a base da panícula até o ápice. Foram realizados a contagem de inflorescências por planta e o número de flores por inflorescência. A duração da abertura floral por inflorescência foi determinada tomando a data da abertura da primeira e da última flor na mesma inflorescência. O comprimento e diâmetro do botão floral foram determinados com um paquímetro digital, em 30 flores. O número de anteras por flor foi quantificado em 30 flores em estádio de pré antese.

Para determinar o número de grãos de pólen por antera, foi utilizada a metodologia adaptada de Petri et al. (1976). Quatro anteras por flor (em préantese) foram mergulhadas em $500 \mu \mathrm{L}$ de ácido lático $(80 \%)$, maceradas e agitadas para manter os grãos de pólen em suspensão. Foi retirada uma gota de $1,5 \mu \mathrm{L}$ e depositada em uma lâmina reticulada, para a contagem total no microscópio óptico. Foram utilizadas 30 flores, totalizando 30 contagens. O número de grãos de pólen por antera foi calculado utilizando a fórmula:

$$
\mathrm{N}=\mathrm{X} \cdot \frac{500 \mu \mathrm{L}}{1,5 \mu \mathrm{L}} \cdot \frac{1}{4}
$$

Onde, $\mathrm{N}$ é o número de grãos de pólen por antera e X é o número de grãos de pólen contados por lâmina.

Foram realizados cortes longitudinais e transversais do ovário de 30 flores para determinar o número de óvulos por flor. A razão pólen/óvulo foi obtida dividindo o número de grãos de pólen pelo número de óvulos por flor (Cruden, 1977).

O volume do néctar (Dafni, 1992), foi determinado com o auxílio de tubos microcapilares de $20 \mu \mathrm{L}$. Foram ensacadas 50 flores na pré-antese e após 24 horas foi avaliado o néctar potencial. $O$ néctar instantaneamente disponível foi avaliado em dois horários: 9:00h e 15:00h, sendo utilizadas 30 flores não ensacadas em cada coleta. A concentração de sólidos solúveis totais ( ${ }^{\circ}$ Brix) do néctar foi medida com um refratômetro portátil com escala de 0 a $30^{\circ}$ Brix (Bellingham \& Stanley, modelo Eclipse).

A receptividade do estigma foi testada utilizando peróxido de hidrogênio a 10\% (Galen \& Plowright, 1987), sendo considerado receptivo o estigma que apresentou reação de efervescência observada em estereomicroscópio. Foram avaliados quatro estádios maturação da flor: dia da antese, um dia, dois dias e três dias após a antese.

\section{Visitantes florais}

As observações foram realizadas durante quatro dias, em períodos de 30 minutos, das 8:00h até às 18:00h, com intervalos regulares de duas horas (Sakagami et al., 1967). Foram considerados visitantes florais legítimos somente aqueles que tocavam a antera ou estigma. Os insetos coletados foram transferidos para um tubo mortífero contendo cianeto de potássio e posteriormente congelados a $-24^{\circ} \mathrm{C}$. Estes foram identificados através de consulta a bibliografia especializada (Silveira et al., 2002; Michener, 2007). Os espécimes foram depositados no Museu entomológico do Laboratório de Entomologia Agrícola da Universidade Federal de Santa Catarina.

\section{Sistema Reprodutivo}

Foram realizados testes de polinização manual em 10 inflorescências de 10 indivíduos distintos empregando-se os seguintes tratamentos: 1) Polinização aberta: flores sob condições naturais; 2) Autopolinização espontânea: flores ensacadas no dia em que antecedeu a antese; 3) Autopolinização manual: flores emasculadas e polinizadas com pólen proveniente de flores da mesma planta na pré-antese; 4) Polinização cruzada manual: flores emasculadas e polinizadas com pólen proveniente de plantas distintas na pré-antese; 5) Partenocarpia: flores emasculadas e ensacadas na pré-antese. A frutificação efetiva foi avaliada 30 dias após a polinização.

Para analisar o crescimento do tubo polínico, foram coletados pistilos polinizados a cada duas horas, até completar 10 horas após a polinização. Os pistilos foram fixados em FAA $(5 \mathrm{ml}$ de formol, $5 \mathrm{ml}$ de Ácido Acético e $90 \mathrm{ml}$ de álcool $70 \%$ ) por um período de 24 horas. Em seguida permaneceram em $\mathrm{NaOH} 9 \mathrm{~N}$ por 15 minutos e posteriormente foram lavados três vezes com água destilada. O material foi transferido para uma lâmina com azul de anilina e observado em microscópio de epiflorescência, com filtros na faixa de $450 \mathrm{~nm}$.

\section{Analises estatística}

Os dados foram apresentados como média $(X) \pm$ desvio padrão (SD). Quando necessário foram submetidos ao teste de Shapiro-Wilk e teste de Bartlett para verificar a normalidade e homocedasticidade, respectivamente. Para determinar diferencias entre as variáveis foi realizada a análise de variância (ANOVA) $(P<0,05)$.

\section{RESULTADOS E DISCUSSÃO Morfologia floral}

A planta de $A$. saponaria, forma apenas uma inflorescência ramificada, que tende a ser densamente florida e colorida. Foram emitidas 267 \pm 92,7 flores por inflorescência, com um período de abertura floral de aproximadamente 14 dias (Tabela 
1). As flores apresentaram sua antese ao longo do dia, o que permitiu aos visitantes florais encontrar flores em vários estádios fenológicos na mesma inflorescência. As flores encontraram-se dirigidas para baixo durante a floração, são actinomorfas, hermafroditas e tubulares de coloração laranjavermelhada, sendo o ápice das tépalas de cor amarela. As flores são levemente avultadas na região basal, onde apresentam um diâmetro médio de 6,4 $\pm 0,4 \mathrm{~mm}$ (Figura 1a). Cada flor apresenta em média 356.216,6 grãos de pólen, distribuídos em 6 anteras basifixas com deiscência longitudinal. $O$ ovário é supero, alongado, trilocular, apresentando duas filas de óvulos por lóculo (Figura 1b, 1c).

O número de flores por inflorescência é maior ao encontrado previamente para esta espécie naturalizada na Venezuela (Velásquez-arenas \& Imery-Buiza, 2008). Porém, o comprimento e diâmetro das flores foram semelhantes (Velásquezarenas \& Imery-Buiza, 2008). Segundo Reynolds (1982), A. saponaria é inquestionavelmente o Aloe manchado mais variável de todos, devido provavelmente à ampla gama de condições nas quais é encontrada desde o nível do mar até 1800 metros de altitude.

A razão Pólen/óvulo foi de 4.608,2: 1 caracterizando esta espécie como xenogâmica (Cruden, 1977), ou seja, dependente da polinização cruzada para obter seu sucesso reprodutivo. $O$ néctar potencial das flores apresentou um volume médio de 16,6 $\pm 6,3 \mu \mathrm{L}$ com uma concentração de sólidos solúveis totais $22 \pm 2,4{ }^{\circ}$ Brix. As médias de produção de néctar instantâneo e a sua concentração de açúcares durante os períodos matutinos e vespertinos não apresentaram diferença significativa segundo a análise de variância (ANOVA) $(P<0,05)$.

Os valores das concentrações de sólidos solúveis totais no néctar das flores para esta espécie foram similares aos encontrados por VelásquezArenas \& Imery-Buiza (2008), sob as condições ambientais do bosque seco tropical. No presente trabalho, este recurso floral mostrou-se disponível em grandes quantidades durante o dia todo. Esta característica é vantajosa, pois permite aumentar o número de flores visitadas pelos polinizadores. A concentração parece estar relacionada com o volume de néctar produzido na flor. Por exemplo, Aloe marlothii também apresenta flores tubulares cor laranja a vermelha, porém, elas produzem uma quantidade de néctar muito alta $\left(250 \mu \mathrm{L}\right.$.flor $\left.{ }^{-1}\right) \mathrm{com}^{-1}$ uma concentração de $12 \%$ de sólidos solúveis totais (Symes \& Nicolson, 2008). Em contraste as flores da espécie Aloe greatheadii var. davyana produzem menos néctar (33 $\mu \mathrm{L}$.flor-1) com uma concentração mais elevada (21\%) (Human \& Nicolson, 2008).

Pode-se observar uma baixa receptividade dos estigmas no dia da antese, a qual aumentou consideravelmente até o segundo dia após a abertura floral. A partir deste momento a receptividade começou a declinar, e no terceiro dia após a antese não foi identificada. Por outro lado, a liberação dos grãos de pólen iniciou junto com antese, sendo que o estigma se encontra mais receptivo após a deiscência das anteras. Isto ratifica a dicogamia nestas flores, de tipo protandria,

TABELA 1. Características morfológicas das inflorescências de Aloe saponaria em Florianópolis, Santa Catarina. Valores médios $(X) \pm$ desvio padrão (SD). SST: de sólidos solúveis totais.

\begin{tabular}{lc}
\hline \multicolumn{1}{c}{ Características } & X \\
\hline Comprimento da inflorescência (cm) & $105 \pm 0,1$ \\
Número de inflorescência por planta & $1,0 \pm 0,0$ \\
Número de flores por inflorescência & $267 \pm 92,7$ \\
Duração da abertura floral por inflorescência (dias) & $14 \pm 3$ \\
Comprimento da flor (cm) & $3,2 \pm 0,2$ \\
Diâmetro da flor (mm) & $6,4 \pm 0,4$ \\
Anteras por flor & $6 \pm 0,0$ \\
Pólen/flor & $356.216,6$ \\
Óvulos/flor & 77,3 \\
Razão Pólen/óvulo & $4.608,2: 1$ \\
Volume do néctar potencial $(\mu \mathrm{L})$ & $16,6 \pm 6,3$ \\
Concentração de SST no néctar potencial ( ${ }^{\circ}$ Brix) & $22 \pm 2,4$ \\
Volume do néctar Instantâneo $(\mu \mathrm{L})$ & $11,6 \pm 4,7$ \\
Concentração de SST no néctar Instantâneo ( ${ }^{\circ}$ Brix) & $20,2 \pm 1,7$ \\
\hline
\end{tabular}

Rev. Bras. PI. Med., Campinas, v.17, n.4, supl. I, p.713-721, 2015. 

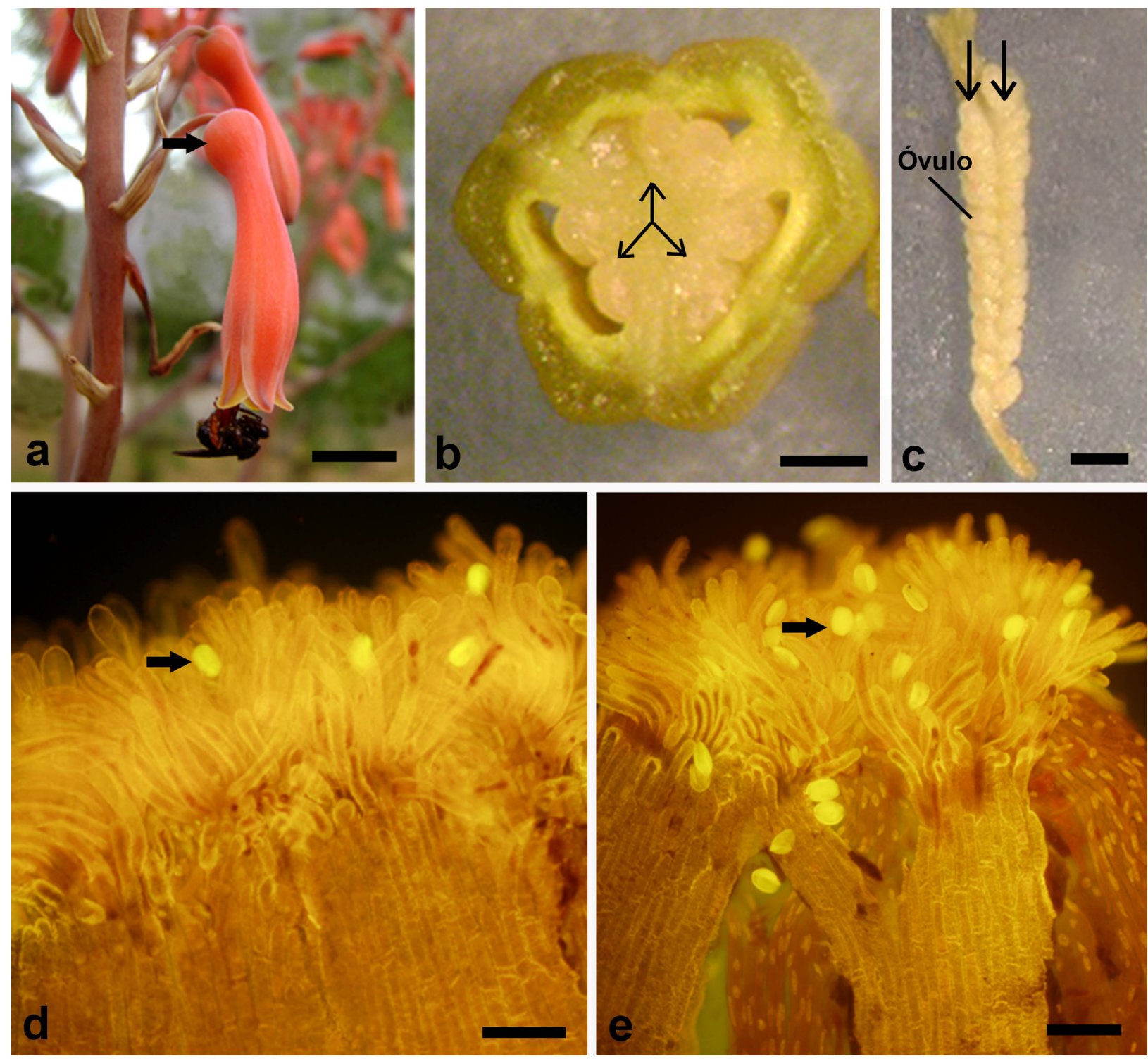

FIGURA 1. Flores de Aloe saponaria em Florianópolis, Santa Catarina. a. Flores tubulares levemente avultadas na região basal (seta); b. Corte transversal do ovário trilocular (setas); c. Visão longitudinal do ovário mostra as duas filas (setas) de óvulos presentes em cada lóculo; d-e. Imagem no microscópio de epifluorescência: $\mathbf{d}$. Estigma com grãos de pólen sem germinar após 2 horas da polinização; e. Estigma com grãos de pólen sem germinar após 10 horas da polinização. Barras: a: $1 \mathrm{~cm}$; b-c: $1 \mathrm{~mm}$; d-e: $100 \mu \mathrm{m}$

reportado previamente para esta espécie por Velásquez-Arenas \& Imery-Buiza (2008).

\section{Visitantes florais}

Segundo Xena \& Madriz, (1994) a cor amarela e laranja-vermelha nas flores permitem atrair um grupo variado de visitantes florais. Desta forma, nas inflorescências de $A$. saponaria foi coletado um total de 110 insetos, os quais pertencem a três ordens: Diptera, Hemiptera e Hymenoptera (Tabela 2). A ordem Hymenoptera foi a mais abundante com 104 insetos coletados $(94,5 \%)$, os quais pertencem às famílias: Apidae, Halictidae e Vespidae. A espécie mais frequente foi Trigona (Trigona) spinipes, sendo responsável pelo $61,8 \%$ das visitas. Nas espécies $A$. vera e A. saponaria, Velásquez-Arenas \& Imery-Buiza (2008) só encontraram visitantes florais da ordem Hymenoptera, sendo Apis mellifera a espécie que apresentou maior número de indivíduos. Segundo Hargreaves et al. (2012), as características florais específicas de cada espécie, especialmente a acessibilidade ao néctar e a dicogamia, controlam a eficiência das abelhas coletoras de pólen como polinizadores das espécies Aloe.

A espécie Trigona (Trigona) spinipes é considerada de caráter generalista (Johnson e Steiner, 2000), com efeitos negativos sobre diversas espécies vegetais, devido a sua atividade pilhadora, realizando orifícios na base da corola

Rev. Bras. PI. Med., Campinas, v.17, n.4, supl. I, p.713-721, 2015. 
para a extração ilegítima do néctar (Krieck et al., 2008; Hargreaves et al., 2009). No entanto, durante as visitas às flores de $A$. saponaria, não foi observado este tipo de atividade, uma vez que os indivíduos de $T$. spinipes ingressavam pela abertura da corola e posteriormente saiam com uma massa de pólen aderida às corbículas das pernas posteriores, sendo evidente sua atividade coletora de pólen. Muller et al. (2006) indicam que essa coleta é realizada para alimentar suas larvas. Provavelmente o maior impacto do comportamento destas abelhas está relacionado com sua eficiente capacidade de remoção do pólen, não obstante, fornece pouca ou nenhuma transferência de pólen entre plantas, deixando pouco pólen disponível para outros polinizadores (Thomson \& Thomson, 1992; Hargreaves et al., 2009). Na África, tem sido relatado que a atividade das abelhas pilhadoras, pode reduzir o sucesso reprodutivo das populações de A. maculata (Hargreaves et al., 2010), assim como em outras espécies de Aloe (Botes et al., 2009).

O pico de visitação ocorreu das 12:00 às $12: 30 \mathrm{com}$ um total de 29 insetos coletados a uma temperatura média de $26,5 \pm 1,5^{\circ} \mathrm{C}$ (Figura 2). A diminuição da visitação ocorreu no final do dia (18:00 horas), período onde apresentou-se uma queda na temperatura. Segundo VitaliVeiga \& Machado (2001), T. spinipes é um dos visitantes mais frequentes nas flores da leguminosa Gleditsia triacanthos, apresentando uma correlação significativa com a temperatura do ambiente, pois sua maior atividade foi observada durante as horas mais quentes do dia.

Além dos insetos, foi observada uma espécie de beija-flor da família Trochilidae (Ordem: Apodiformes) visitando as flores de $A$. saponaria. Velásquez-Arenas \& Imery-Buiza (2008) observaram este tipo de aves como visitantes florais nessa espécie. Cronquist (1981) sugere a síndrome de polinização ornitofílica para a maioria das espécies do gênero Aloe que apresentam flores de tamanho igual ou superior ao encontrado em $A$. saponaria. Segundo Johnson \& Nicolson (2008), as propriedades do néctar estão associadas com a especificidade da polinização por aves, sendo que flores que produzem um alto volume de néctar (40-100 $\left.\mu \mathrm{L}_{\text {.flor }}{ }^{-1}\right)$ e baixa concentração de sólidos solúveis totais (8-12\%) atrai polinizadores generalistas, enquanto que um baixo volume de néctar (10-30 $\mu \mathrm{L}$./flor-1) com maior concentração (15-25\%), atrai nectarivoros especializados, como os beija-flores. Segundo Hargreaves et al. (2012), o

TABELA 2. Visitantes florais coletados sobre flores de Aloe saponaria em Florianópolis, Santa Catarina.

\begin{tabular}{|c|c|c|}
\hline Ordem/Família & Espécie & $\mathrm{N}$ \\
\hline DIPTERA $(4,5 \%)$ & & 5 \\
\hline \multirow[t]{2}{*}{ Asilidae } & sp.1 & 2 \\
\hline & sp.2 & 1 \\
\hline \multirow[t]{2}{*}{ Sarcophagidae } & sp.1 & 1 \\
\hline & sp.2 & 1 \\
\hline HEMIPTERA $(0,9 \%)$ & & 1 \\
\hline Pentatomidae & sp.1 & 1 \\
\hline HYMENOPTERA $(94,5 \%)$ & & 104 \\
\hline \multirow[t]{5}{*}{ Apidae } & Apis mellifera & 1 \\
\hline & Plebeia droryana & 4 \\
\hline & Trigona (Trigona) spinipes & 68 \\
\hline & Xylocopa (Xylocospila) bambusae & 1 \\
\hline & Xylocopa (Stenoxylocopa) artifex & 1 \\
\hline \multirow[t]{5}{*}{ Halictidae } & Augochlora sp1. & 1 \\
\hline & Augochlora sp2. & 1 \\
\hline & Augochlora sp.3 & 1 \\
\hline & Augochlorella sp.1 & 1 \\
\hline & Augochloropsis sp.1 & 2 \\
\hline \multirow[t]{2}{*}{ Vespidae } & sp.1 & 22 \\
\hline & sp.2 & 1 \\
\hline TOTAL & & 110 \\
\hline
\end{tabular}

Rev. Bras. PI. Med., Campinas, v.17, n.4, supl. I, p.713-721, 2015. 
comportamento do inseto pode limitar a quantidade e a qualidade do pólen depositado no estigma, considerando que os insetos se movem com menos frequência entre as plantas do que os pássaros.

\section{Sistema Reprodutivo}

Os resultados indicam a presença de incompatibilidade em $A$. saponaria, uma vez que as flores submetidas aos tratamentos de polinizações não formaram frutos. Isto pode ser explicado pela inibição da germinação do pólen e crescimento do tubo polínico, evidenciado mediante a microscopia de epifluorescência (Figura 1d; 1e). Portanto, além da protandria nesta espécie, existe outro mecanismo complementar, relacionado à incompatibilidade esporofítica, que regula a germinação do pólen e o crescimento do tubo polínico dentro do pistilo. A incompatibilidade esporofítica ocorre na superfície do estigma ou logo após sua penetração e está envolvida com substâncias secretadas na superfície das papilas estigmáticas (Bueno et al., 2006).

Estudos em populações naturais em Sudáfrica consideram $A$. saponaria uma espécie autoincompatível, devido a um mecanismo tardio que age no ovário (Hargreaves et al., 2012). Nas plantas Aloe, com sistemas de autoincompatibilidade de ação tardia, a autopolinização pode ser especialmente cara, já que leva à redução do óvulo, o que pode reduzir fortemente a produção de sementes (Hargreaves et al., 2012). No entanto, a germinacão do pólen, também pode estar relacionada com a existência de algumas anormalidades genéticas na microsporogênese referidas previamente para o gênero Aloe (Imery \& Cequea, 2002; Imery-Buiza, 2007), as quais são favorecidas pela acumulação de mutações através da propagação assexual (ImeryBuiza \& Cequea-Ruiz, 2008).

A espécie $A$. saponaria é considerada xenogâmica, uma vez que Cruden (1977) assinala que este tipo de sistema reprodutivo, está relacionado com plantas geralmente autoincompatíveis, que apresentam protandria, e que requerem de polinizadores para seu sucesso reprodutivo. De acordo com isso, vários autores citam que a maioria das espécies do gênero Aloe são autoincompatíveis e protandricas (Newton, 2004; Smith \& Steyn, 2004; Imery-Buiza \& Cequea-Ruiz, 2008) e dependem de visitantes florais para a polinização (Botes et al., 2009). Contudo, a ausência de frutificação em $A$. saponaria não foi consequência da falta de polinizadores, visto que no local de estudo observamos a presença de visitantes florais que transportaram o pólen até o estigma. Populações naturais da espécie $A$. vera na África formam frutos com sementes (Carter, 1994), porém, populações de $A$. vera naturalizadas na Venezuela, não frutificam, apesar de ocorrer a visitação de numerosos polinizadores durante a floração. Isto indica que as diferenças de latitude e as condições climáticas no local de estudo podem incidir sobre o desenvolvimento floral, características do pólen ou receptividade do pistilo (Imery-Buiza \& CequeaRuiz, 2008). Além disso, também influencia a menor diversidade genética dentro de suas populações considerando que as plantas estão localizadas fora do centro de origem primário (Imery-Buiza \& Cequea-Ruiz, 2008).

Plantas de $A$. vera introduzidas em algumas outras regiões do mundo apresentam propagação exclusivamente vegetativa (Natali et al., 1990). Este modo de reprodução tende a predominar em ambientes que são desfavoráveis para o recrutamento sexual e tem consequências ecológicas sobre a fecundidade, especialmente em plantas autoincompatíveis (Eriksson 1993; VallejoMarín et al. 2010). A propagação vegetativa leva a

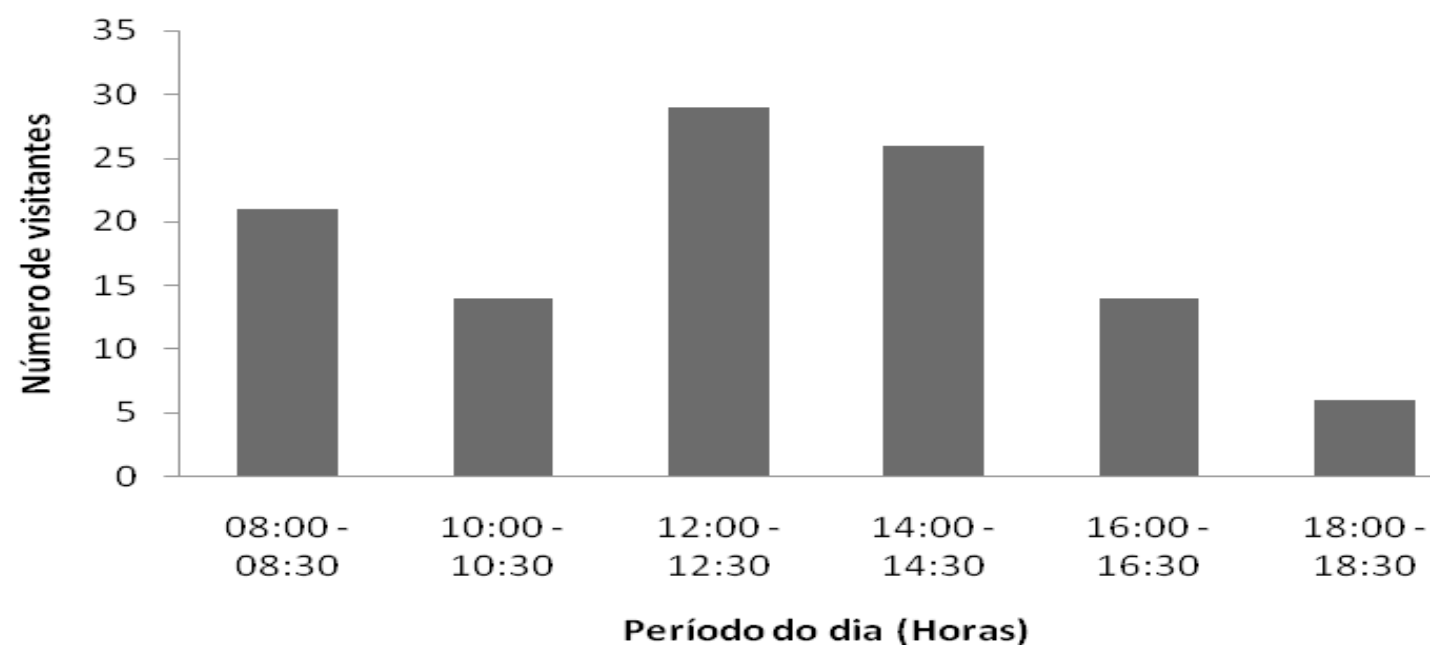

FIGURA 2. Número total de visitantes florais de Aloe saponaria coletados em intervalos de duas horas, durante 4 dias em Florianópolis, Santa Catarina.

Rev. Bras. PI. Med., Campinas, v.17, n.4, supl. I, p.713-721, 2015. 
uma redução da variabilidade nas populações de Aloe naturalizadas (Imery \& Cequea 2002; Albornoz \& Imery, 2003) e consequentemente, torna essas populações mais vulneráveis à doenças e pragas, prejudicando sua capacidade de se adaptarem às mudanças ambientais.

A combinação desses fenômenos biológicos restringe a reprodução sexual de $A$. saponaria em Florianópolis, onde provavelmente sua população tem se estabelecido principalmente pela propagação vegetativa a partir de um ou poucos espécimes introduzidos na região. Nesse caso, promover novas combinações genéticas mediante cruzamentos interespecíficos seria uma estratégia para favorecer o aumento da variabilidade genética das Aloe no local estudado.

\section{CONCLUSÃO}

Apesar da produção considerável de néctar, a presença de polinizadores, e a receptividade do estigma na população ex-situ de $A$. saponaria em Florianópolis, não houve frutificação efetiva. Isto pode estar relacionado com outros fatores, como a existência de um mecanismo de autoincompatibilidade esporofítica, a presença de anormalidades cromossômicas no pólen, as condições climáticas, ou a escassa variabilidade genética no local de estudo. Consequentemente, as expectativas da reprodução sexual nessa população de $A$. saponaria, são reduzidas, limitando o recrutamento de novos indivíduos.

\section{REFERÊNCIAS}

ALBORNOZ, A.A.; IMERY, B.J. Evaluación citogenética de ocho poblaciones de Aloe vera L. de la península de Araya-Venezuela. Ciencia, v.11, n.1, p.5-13, 2003.

BOTES, C.; et al. The birds and the bees: using selective exclusion to identify effective pollinators of African tree Aloes. International Journal of Plant Science, v.170, n.2, p.151-156, 2009.

BUENO, L.C.DE S.; MENDES, A.N.G.; CARVALHO, S.P. Melhoramento genético de plantas: princípios e procedimentos. 2. ed. Lavras: UFLA, 2006. 319p.

CARTER, S. Flora of tropical east Africa, Aloaceae. U.K.: Royal Botanic Garden, 1994. 61p.

CENTRO DE ESTUDOS CULTURA E CIDADANIA CECCA. Uma cidade numa ilha. Florianópolis: Ed. Insular, 1997. 248p.

CRONQUIST, A. An integrated system of classification of flowering plants. New York: Columbia University Press, 1981. 1262p.

CRUDEN, R.W. Pollen-ovule ratio: a conservative indicator of breeding system in flowering plants. Evolution, v.31, p.32-46, 1977.

DAFNI, A. Pollination ecology - A practical approach. Oxford: Oxford University Press, 1992. 250p.
DAFNI, A.; KEVAN, P.G.; HUSBAND, B.C. (Eds.). Practical Pollination Biology. Cambridge: Enviroquest, Ltd., 2005. 590p.

EGGLI, U.; NEWTON, L.E.; ROWLEY, G.D. CITES Aloe and Pachypodium Checklist. London: Royal Botanic Gardens, 2001. 165p.

ERIKSSON, O. Dynamics of genets in clonal plants. Trends in Ecology \& Evolution, v.8, p.313-316, 1993.

GALEN, C.; PLOWRIGHT, R.C. Testing the accuracy of using peroxidase actity to indicate stigma receptive. Canadian Journal of Botany, v.65, p.11-107, 1987.

GRACE, O.M. Current perspectives on the economic botany of the genus Aloe L. (Xanthorrhoeaceae). South African Journal Of Botany, v.77, p.980 - 987, 2011.

GRACE, O.M.; et al. Chemosystematic evaluation of Aloe section Pictae (Asphodelaceae). Biochemical Systematics and Ecology, v.38, p.57-62, 2010.

HARGREAVES, A.L.; et al. Consumptive emasculation: the ecological and evolutionary consequences of pollen theft. Biological Reviews, v.84, p.259-276, 2009.

HARGREAVES, A.L.; et al. Native pollen thieves reduce the reproductive success of a hermaphroditic plant, Aloe maculata. Ecology, v.91, n.6, p.1693-1703, 2010.

HARGREAVES A.L.; et al. Floral traits mediate the vulnerability of aloes to pollen theft and inefficient pollination by bees. Annals of Botany, v.109, p.761772, 2012.

HUMAN, H.; NICOLSON, S.W. Flower structure and nectar availability in Aloe greatheadii var. davyana: an evaluation of a winter nectar source for honeybees. International Journal of Plant Sciences, v.169, p.263-269, 2008.

IMERY-BUIZA, J. Inestabilidad cariológica durante la formación de células madres del polen en Aloe vera (Aloaceae). Revista de Biología Tropical (International Journal of Tropical Biology and Conservation ISSN0034-7744) v.55, n.3-4, p.805-813, 2007.

IMERY-BUIZA, J.; CÁRDENAS-RAMÍREZ, Y. Durabilidad de la capacidad germinativa del pólen de Aloe vera (L.) Burm. F. y A. saponaria Haw. Revista UDO Agricola, v.6, n.1, p.67-75, 2006.

IMERY, J.; CEQUEA, H. Anormalidades cromosómicas en la microsporogénesis de Aloe vera (L.) Burm.f. (Aloaceae). Acta Botánica Venezuelica, v.25, p.143152, 2002.

IMERY-BUIZA, J.; CEQUEA-RUIZ, H. Autoincompatibilidad y protandría en poblaciones naturalizadas de Aloe vera de la Península de Araya - Venezuela. Polibotánica, v.26, n.2, p.113-125, 2008.

JOHNSON, S.D.; NICOLSON, S.W. Evolutionary associations between nectar properties and specificity in bird pollination systems. Biology Letters, v.4, p.49-52, 2008.

JOHNSON, S.D.; STEINER, K.E. Generalization versus specialization in plant pollination systems. Trends in Ecology and Evolution, West Sussex, v.15, n.4, p.140-143, 2000.

KLOPPER, R.R.; et al. The genus Aloe L. (Asphodelaceae: Alooideae) in the Free State Province of South Africa. Haseltonia, v.15, p.41-52, 2009.

KÖPPEN, W. Climatologia. México: Fondo de Cultura Económica, 1948. 478p.

KRIECK, C.; et al. Biologia reprodutiva de Alpinia zerumbet

Rev. Bras. PI. Med., Campinas, v.17, n.4, supl. I, p.713-721, 2015. 
(Pers.) B.L.Burtt \& R.M.Sm. (Zingiberaceae) em Florianópolis, Santa Catarina. Revista Brasileira de Plantas Medicinais, v.10, n.2, p.103-110, 2008.

MASCOLA, N.; IZZO, A.; BORRELLI, F.; CAPASSO, R. Healing powers of Aloes. In: REYNOLDS, T. (Ed.). Aloes: The genus Aloe. Boca Raton: CRC Press, 2004. p.210-40.

MICHENER, C.D. The bees of the world. Baltimore: Johns Hopkins University Press, 2007. 913p.

MULLER, A.; et al. Quantitative pollen requirements of solitary bees: implications for bee conservation and the evolution of bee-flower relationships. Biological Conservation, v.130, p. 604-615, 2006.

NATALI, L.; CASTORENA, I.; CAVALLINI, A. In vitro culture of Aloe barbadensis Mill. micropropagation from vegetative meristems. Plant Cell, Tissue \& Organ Culture, v.20, p.71-74, 1990.

NEWTON, L.E. 2004. Aloes in habitat. In: REYNOLDS, T. (Ed.). Aloes: The genus Aloe. Boca Raton: CRC Press, 2004. p.1-14.

PETRI, J.L. Número de grãos de pólen por antera em diversas cultivares de macieira (Malus Sylvestris). Anais do terceiro Congresso Brasileiro de Fruticultura, Campinas: Sociedade Brasileira de Fruticultura, 1976. p. 467-471.

REYNOLDS, D.R. The Aloes of South Africa, 4.ed. Cape Town: A.A. Balkema, 1982. 538p.

SAKAGAMI, S.F.; LAROCA, S.; MOURE, J.S. Wild bee biocenotics in São José dos Pinhais (PR) South Brazil. Preliminary report. Journal of the Faculty of Science, Hokkaido University. Series 6, Zoology, v.16 n.2, p.253-291, 1967.

SAMPEDRO, C.M.; et al. Mannan from Aloe saponaria inhibits tumoral cell activation and proliferation. International Immunopharmacology, v.4, p.411-418, 2004.

SEBBENN, A.M.; et al. Variação genética entre e dentro de populações de amendoim - Pterogyne nitens. Scientia Florestalis, n.56, p.29-40, 1999.

SILVA M.A.; et al. Antinociceptive and antiinflammatory effects of Aloe saponaria Haw on thermal injury in rats. Journal of Ethnopharmacology, v.146, p.393-401, 2013.

SMITH, G.F.; STEYN, E.M.A. Taxonomy of Aloaceae. In: REYNOLDS, T. (Ed.). Aloes: The genus Aloe. Boca
Raton: CRC Press, 2004. p.15-30.

SILVEIRA, F.A.; MELO, G.A.R.; ALMEIDA, E.A.B. Abelhas Brasileiras: sistemática e identificação. Belo Horizonte: Fernando A. Silveira, 2002. 254p.

SOUZA, V.C.; LORENZI, H. Botânica sistemática. Nova Odessa: Instituto Plantarum, 2008. 704p.

SYMES, C.T.; NICOLSON, S.W. Production of copious dilute nectar in the bird-pollinated African succulent Aloe marlothii. South African Journal of Botany, v.74, p.598-605, 2008.

THOMSON, J.D.; THOMSON, B.A. Pollen presentation and viability schedules in animal-pollinated plants: consequences for reproductive success. In: WYATT R. (Ed.). Ecology and evolution of plant reproduction. New York: Chapman and Hall, 1992. p.1-25.

VALLEJO-MARÍN, M.; et al. The ecological and evolutionary consequences of clonality for plant mating. Annual Review of Ecology, Evolution, and Systematics, v.41, p.193-213, 2010.

VAN WYK, B.-E.; SMITH, G. Guide to the Aloes of South Africa. Pretoria: Briza Publications, 2008.

VELÁSQUEZ-ARENAS, R.; IMERY-BUIZA, J. Fenología reproductiva y anatomía floral de las plantas Aloe vera y Aloe saponaria (Aloaceae) en Cumaná, Venezuela. Revista de Biología Tropical (International Journal of Tropical Biology and Conservation ISSN-0034-7744) v.56, n.3, p.11091125, 2008.

VITALI-VEIGA, M.J.; V.L.L. MACHADO. Entomofauna visitante de Gleditsia triacanthos L. Leguminosae durante o seu período de floração. Bioikos, v.15, n.1, p.29-38, 2001.

XENA, N.; MADRIZ, R. Aspectos de la biología de polinización en el bosque enano de la cima del "Cerro Copey" (Isla Margarita). Acta Botánica Venezuelica, v.17, p.35-68, 1994.

YOO, E.A; et al. Evaluation of antioxidant, antinociceptive, and anti-inflammatory activities of ethanol extracts from Aloe saponaria Haw. Phytotherapy Research, v.22, p.1389-1395, 2008.

ZAPATA, P.J.; et al. Characterisation of gels from different Aloe spp. as antifungal treatment: Potential crops for industrial applications. Industrial Crops and Products, v.42, p.223-230, 2013.

Rev. Bras. PI. Med., Campinas, v.17, n.4, supl. I, p.713-721, 2015. 